\section{REFERENCES}

Burks, C. D., Hitzing, E. W., \& Schaeffer, R. W. Drinking response distributions associated with a $4 \%$ sucrose FFI food schedule. Psychonomic Science, 1967, 8, 13-14.

Christian, W. P., Jr., \& Schaeffer, R. W. Note: Advisability of using sugar-free food pellets for schedule-induced polydipsia research. Psychological Reports, 1973a, 32, 274.

Christian, W. P., Jr., \& Schaeffer, R. W. Effects of sucrose concentrations upon schedule-induced polydipsia on a FF1-60-sec dry-food reinforcement schedule. Psychological Reports, 1973b, 32, 1067-1073.

Christian, W. P., Jr., Reister, R. W., \& Schaeffer, R. W. Effects of sucrose concentrations upon schedule-induced polydipsia using free and response-contingent dry-food reinforcement schedules. Bulletin of the Psychonomic Society, 1973, 2, 65-68.

Clark, F. C. Some observations on the adventitious reinforcement of drinking under food reinforcement. Journal of the Experimental Analysis of Behavior, 1962, 6, 61-63.

Denny, M. R., \& Ratner, S. C. Comparative psychology. Homewood, Illinois: Dorsey, 1970.

Falk, J. L. Production of polydipsia in normal rats by an intermitten food schedule. Science, 1961, 133, 195-196.

Falk, J. L. Schedule-induced polydipsia as a function of fixed-interval length. Journal of the Experimental Analysis of Behavior, 1966, 9, 37-39.
Falk, J. L. Control of schedule-induced polydipsia: type, size and spacing of meals. Journal of Experimental Analysis of Behavior, 1967, 10, 199-206.

Falk, J. L. Conditions producing psychogenic polydipsia in animals. Annals of the New York Academy of Sciences, 1969, $157,569,593$.

Flory, R. K. The control of schedule-induced polydipsia: Frequency and magnitude of reinforcement. Learning and Motivation, 1971, 2, 215-227.

Hymowitz, N. Effects of lever-press dependent and independent electric shock on schedule-induced water intake. The Psychological Record, 1973, 23, 487-497.

King, G. D. The enhancement of schedule-induced polydipsia by preschedule noncontingent shock. Bulletin of the Psychonomic Society, 1974, 3, 46-48.

Schoenfeld, W. N., Cumming, W. W., \& Hearst, E. On the classification of reinforcement schedules. Proceedings of the National Academy of Sciences, 1956, 42, 563-570.

Segal, E. F., Oden, D. L. \& Deadwyler, S. A. Determinants of polydipsia: IV. Free-reinforcement schedules. Psychonomic Science, 1965, 3, 11-12.

Stein, L. Excessive drinking in the rat: Superstition or thirst? Journal of Comparative and Physiological Psychology, 1964,
58, 237-242.

(Received for publication October 17, 1974.)

\title{
Stimulus distinctiveness and backward associations
}

\author{
DONALD G. WILDEMANN \\ University of North Carolina at Greensboro, Greensboro, North Carolina 27412
}

\begin{abstract}
In two paired-associate experiments, one stimulus was made a distinctive item by making this stimulus a different color from all other items. In subsequent backward-association tests, the distinctive stimulus was emitted as a correct backward association significantly more frequently than other items. In other analyses, the number of correct forward anticipations was computed for each of the nondistinctive pairs and used as a measure of forward associative strength. These analyses showed that stimulus distinctiveness produced a greater effect on backward associations than did forward associative strength. For the nondistinctive pairs, the correlation between the number of correct forward anticipations and the subsequent probability of a correct backward association accounted for less than $6 \%$ of the variance.
\end{abstract}

Most theories of transfer in human paired-associate (PA) learning have proposed that backward associations are a major source of facilitation or interference in transfer (e.g., Kausler, 1974; Merryman, 1971; Postman \& Stark, 1972). An implicit assumption in these theories is that the "strength" of a backward association should vary directly with the strength of the forward association. Since this assumption has rarely, if ever, been directly tested, one purpose of the following

This research was supported by a grant from the Research Council of the University of North Carolina at Greensboro (RCG-605). This paper is sponsored by Robert E. Eason, who takes full editorial responsibility for it. Requests for reprints should be sent to Donald G. Wildemann, Department of Psychology, University of North Carolina at Greensboro, Greensboro, North Carolina 27412. experiments was to provide such a test.

A second purpose of the present study was to contrast the relative effect of stimulus characteristics and the relative effect of forward associative strength on backward associations. Numerous experiments using both infrahuman and human subjects have demonstrated that only part of the experimental stimuli may control a subject's behavior (cf., Kintsch, 1970; Sutherland \& Mackintosh, 1971). As several investigators have noted (e.g., Ekstrand, 1966), if the stimulus actually controlling a subject's behavior (i.e., the functional stimulus) differs from the stimulus presented by the experimenter (i.e., the nominal stimulus), any decrements in the recall of the backward association could be due to this difference. It may, however, be 
possible to make the nominal and functional stimulus more identical by using a distinctive stimulus with one pair in a PA list. During training, if the distinctive pair were presented less frequently than the other pairs, then the forward associative strength of the distinctive item should be less than the forward associative strength of pairs correctly anticipated more frequently in a forward direction (i.e., than other pairs which are overlearned). A comparison of the correct backward associations for such a distinctive pair to the correct backward associations for nondistinctive, but overlearned, pairs should therefore provide an indication of the relative importance of stimulus characteristics and of forward associative strength on backward associations. A second purpose of the following experiments was to provide this comparison.

In the following experiments, distinctiveness of the stimulus was manipulated by making one stimulus in a PA list a color different than that of all of the other items on the list. This distinctive stimulus was also introduced late in training to reduce the item's forward associative strength. The distinctive item was included in a PA list on only the last two anticipation trials. Six other nondistinctive pairs were presented on five anticipation trials. If the number of correct forward anticipations is considered to be a measure of the "strength" of the forward association, then items which are correctly anticipated on 5, 4 , and 3 trials should have a greater forward associative strength than pairs which are correctly anticipated 0,1 , or 2 times. Thus, if the distinctive item was more frequently emitted as a correct backward associate than items which had been correctly anticipated more frequently in a forward direction, then the probability of a correct backward association would be more of a function of stimulus characteristics than of forward associative strength. The first experiment was therefore designed to determine if stimulus distinctiveness has a greater effect on backward associations than does the strength of a forward association.

The second experiment was identical to the first except that a different item was used as the distinctive stimulus. Following completion of the first experiment, the mean number of correct backward associations was calculated for each of the nondistinctive pairs. The pair with the lowest mean number of correct backward associations was then chosen as the distinctive item for the second experiment. Since this pair was presented on five anticipation trials in the first experiment and on only two anticipation trials as a distinctive stimulus in the second experiment, the item should have had the highest forward associative strength in the first experiment. Therefore, a comparison of the number of correct backward associations for this item in the first and second experiments provides a second measure of the relative effects of forward associative strength and of stimulus characteristics on correct backward associations.

\section{METHOD}

\section{Training Materials}

Seven digit-word pairs (026-NAME, 289-LINE, 382-ACT, 571-FEET, 650-HANDS, 705-BODY, and 981-FEET) were employed. The digit stimuli were randomly selected except that the initial digit of each numer had to be different. The words had a Kucera and Francis (1967) frequency ranging from 276-298. All stimuli and responses, except for the distinctive stimuli, were printed in black type.

\section{Subjects and Apparatus}

Forty-eight undergraduate students enrolled in introductory psychology served as subjects. They were randomly assigned to 1 of 4 groups, 12 subjects per group.

Two Gerbrands memory drums were used to present the items. The first three trials were presented on one drum, the remaining four trials on the other drum.

\section{Procedure}

The first trial was a study trial in which each of the seven pairs was presented for $3 \mathrm{sec}$. On Trials 2-5, items were presented by the anticipation method at a $3: 3$ rate with a 6 -sec intertrial interval. Six different pair orders were employed.

For two of the groups, the pair 705-BODY was excluded during the first three anticipation trials; for the other two groups, the pair 289-LINE was excluded during these trials. For all groups, all seven pairs were presented on Anticipation Trials 4 and 5. For the 705 distinctive stimulus group, the 705 was printed in red letters during the last two anticipation trials. Since introducing a stimulus and response pair late in training might make that pair more distinctive than other pairs, a 705 nondistinctive group served as a control. For the 705 nondistinctive group, the 705-BODY pair was printed in black letters and presented on only the last two anticipation trials. An identical procedure was used with the two 289-LINE groups except that 289-LINE was the pair reintroduced late in training.

Throughout training, subjects pronounced each stimulus as it appeared. Following the fifth anticipation trial the drum was stopped and subjects were told that the task would change slightly, but they were to continue to pronounce the stimulus and then to try to say the appropriate response. The backward association test was then presented. During this test, each of the training responses was printed in black letters. Presentation time for each item was $3 \mathrm{sec}$. During this test, the subjects were not told whether or not their responses were correct. Both correct responses and partially correct responses (in terms of one or more digits being correct) were recorded.

\section{RESULTS AND DISCUSSION}

Since the major response of interest was correct or incorrect backward associations of the distinctive item, and since the number of correct backward associations could have a maximum value of 12 , nonparametric statistics were employed in the data analyses.

The manipulation of stimulus distinctiveness resulted in an increased number of correct backward associations. When the 705 was the distinctive stimulus, it was correctly emitted as a backward associate 11 out of 12 times (i.e., on $92 \%$ of the test trials). The nondistinctive pairs were correctly emitted as backward association only 25 out of a possible 72 times (i.e., on $35 \%$ of the test trials). A Fisher's exact probability test showed that this difference was significant $(p=.0003)$.

When the criterion for a correct response for a 
backward association of a nondistinctive pair was lowered to having one or more correct digits without any incorrect digits, the number of correct responses increased from 25 to 39 (i.e., to being correct on $54 \%$ of the test trials). With the lenient scoring, subjects had an additional 11 first digits correct, 2 second digits correct and 1 third digit correct. A Fisher's exact probability test showed that the distinctive stimulus was still emitted significantly more frequently as a correct backward association than the nondistinctive pairs $(p=.015)$.

Stimulus distinctiveness was also a more important determiner of correct backward associations than was forward associative strength. While the distinctive-stimulus item could have been correctly anticipated in the forward direction twice, no subject anticipated this item more than once. If the number of correct forward anticipations reflects the strength of a forward association, then any nondistinctive pair that was correctly anticipated two or more times should have had a greater forward associative strength than the distinctive-stimulus pair. To ensure that items counted as having high forward associative strength did indeed reflect such strength, high associative strength pairs were defined as those pairs which were correctly anticipated three or more times. In the 705 distinctive stimulus group, 34 nondistinctive pairs were anticipated correctly in a forward direction three or more times. Twenty (i.e., $54 \%$ ) of these high strength pairs were correctly emitted as backward associations. Comparing the 20 correct and 14 incorrect backward associations of the high strength pairs to the 11 correct and 1 incorrect backward associations of the distinctive stimulus pair revealed that the distinctive stimulus pair was emitted significantly more often as a backward association (Fisher's exact test, $\mathrm{p}=.036$ ). Therefore stimulus distinctiveness had a significantly greater effect on backward associations than did the strength of the forward association.

The effect of the stimulus distinctiveness was produced by the color of the stimulus rather than by the late introduction of this pair. In the distinctive control condition where the 705 was introduced in black type, only 4 out of 12 subjects subsequently emitted correct backward associations to this item. When this result was compared to the 11 out of 12 correct responses for the same pair when the stimulus was red in training, a Fisher's exact probability test confirmed that the red color had a significant effect $(p-.009)$.

Finally mean values for correct backward associations for the nondistinctive items in the first experiment ranged from a low of .29 for 289-LINE, 571-FEET, and 650-HANDS to a high value of .62 for the pair 026-NAME. Of the three pairs with the lowest values, 289-LINE was randomly chosen as the distinctive pair for the second experiment.

The pair 289-LINE was correctly anticipated in a forward direction many more times in the first experiment than in the second experiment. On the two anticipation trials in the second experiment when 289-LINE was the distinctive item, the pair was correctly anticipated by only $29 \%$ of the subjects. In contrast, in the first experiment when this pair was present on five anticipation trials, it was correctly anticipated on $48 \%$ of the presentations. Since the 289-LINE pair had been correctly anticipated many more times in the first than in the second experiment, the forward associative strength of this pair should have been greater in the first experiment. The distinctive pair, however, was correct as a backward association most frequently. In the second experiment, the distinctive pair 289-LINE was emitted as a correct backward association 8 out of 12 times while it had been correct on only 7 out of 24 test trials in the first experiment. These differences were significant at a .08 level of confidence $\left(\mathrm{X}^{2}=3.21, \mathrm{p}=.08\right)$.

In the second experiment, both the distinctive item and the nondistinctive control item were anticipated almost equally frequently in a forward direction. The distinctive item, however, was emitted significantly more frequently as a correct backward association (Fisher's exact probability test, $\mathrm{p}=.0047)$. Therefore the increased number of correct backward associations in the second experiment, as in the first experiment, was produced by the color of the stimulus rather than by the late introduction of this pair.

Finally, to determine the relationship between forward associative strength and the number of correct backward associations, a point-biserial correlation was calculated between the number of correct forward anticipations for all of the nondistinctive items in the two experiments and the number of correct backward associations. While this correlation was significant $\left(r_{\mathrm{pb}}[2.86]=.21, \mathrm{p}<.001\right)$, the correlation accounts for less than $6 \%$ of the variance. Therefore, while forward associative strength, as measured by the number of correct forward anticipations, is related to the subsequent probability of a correct backward association, other factors, such as stimulus distinctiveness, produce greater effects.

\section{REFERENCES}

Ekstrand, B. R. Backward associations. Psychological Revlew, $1966,65,50-64$.

Kausler, D. H. Psychology of verbal learning and memory. New York: Academic Press, Inc., 1974.

Kintsch, W. Learning, memory and conceptual processes. New York: Wiley, 1970.

Kucera, H., \& Francis, W. N. Computational analysis of present-day American English. Providence, R. I: Brown University Press, 1967.

Merryman, C. T. Retroactive inhibition in the A-B, A-D paradigm as measured by a multiple-choice test. Journal of Experimental Psychology, 1971, 91, $212-214$.

postman, L., \& Stark, $K$. On the measurement of retroactive inhibition in the A-B, A-D paradigm by the multiple-choice method: reply to Merryman. Journal of Verbal Learning and Verbal Behavior, 1972, 7, 672-694.

Sutherland, N. Mackintosh, N. J. Mechanisme of animal discrimination learning. New York: Acadomlc Press, 1971.

(Received for publication October 11, 1974.) 